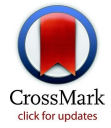

${ }^{1}$ University of Exeter, Exeter EX1 2LU, UK

${ }^{2}$ London Borough of Hillingdon, Uxbridge UB8 1UW, UK

${ }^{3}$ National Collaborating Centre for Cancer, Cardiff CF10 3AF, UK Correspondence to: mailto: $\mathrm{W}$ Hamilton w.hamilton@exeter.ac.uk Cite this as: BMJ 2015;350:h3036 doi: 10.1136/bmj.h3036

This is one of a series of $B M$ J summaries of new guidelines based on the best available evidence; they highlight important recommendations for clinical practice, especially where uncertainty or controversy exists.

\title{
Suspected cancer (part 1-children and young adults): visual overview of updated NICE guidance
}

\author{
William Hamilton, ${ }^{1}$ Steve Hajioff, ${ }^{2}$ John Graham, ${ }^{3}$ Mia Schmidt-Hansen ${ }^{3}$
}

It is generally believed that early diagnosis of cancer reduces mortality and morbidity. The National Institute for Health and Care Excellence (NICE) has updated its 2005 guidance on the recognition and referral from primary care of people with suspected cancer. ${ }^{1}$ This summary of the full guidance is in two parts: part 1 on recommendations for children (up to 15 years old) and young adults (16-24 years), and part 2 on those for adults. Separate recommendations have been made for adults and for children and young people to reflect that there are different referral pathways. However, in practice young people (aged 16-24) may be referred using either an adult or children's pathway depending on their age and local

\section{HOW PATIENTS WERE INVOLVED}

Committee members involved in this guideline update included lay members who contributed to the formulation of the recommendations summarised here.

arrangements. The full guidance will be available on thebmj.com.

Key changes in the updated guidance are:

- Reliance on new evidence derived from primary, rather than secondary, care

- Explicit use of a threshold risk of cancer to underpin recommendations for urgent investigation-the first cancer guidance to do so. ${ }^{2}$

\section{Assessing and referring childhood cancers}

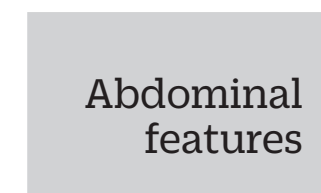

Lumps
or masses
(non-
abdominal)

Bleeding

Neurological
Non-specific features

Skeletal

\section{Splenomegaly unexplained + Fever Sweats Breathlessness Pruritus Weight loss \\ Hepatosplenomegaly unexplained}

Abdominal mass palpable Enlarged organ unexplained

\section{Lymphadenopathy + Fever Sweats Breathlessness Pruritus Weight loss}

Soft tissue lump unexplained growing

Lymphadenopathy generalised

\section{Haematuria visible unexplained}

\section{Petechiae unexplained}

\section{Bleeding Pallor Bruising unexplained}

\section{Abnornal Cerebellar other central neurological function}

Absent red reflex

Fatigue persistent

Fever unexplained

Infection unexplained persistent

Bone pain persistent/unexplained

Bone swelling Bone pain unexplained 
This guidance:

- Assumes that patients will have had a full history, clinical examination, and appropriate initial blood tests

- Recommends urgent investigation in adults with a 3\% or higher cancer risk, but uses a lower threshold for children and young people and when primary care testing is available

- Relies on evidence mainly from moderate quality observational studies. The evidence base for each recommendation is incorporated in the full guidance, but has been omitted here for ease of reading.

- Will increase the number of investigations or referrals in some cancer sites; the use of direct access testing should reduce the costs of this, but will require organisational change

- Asks clinicians to continue to trust their clinical experience where there are particular reasons that the guidance isn't relevant to a patient's specific presentation.

\section{Recommendations}

The figure lists symptoms of possible childhood cancer, the cancers that may underlie these symptoms, and the recommended investigations or referral.

1) Turquoise-primary care investigation

2) Purple-referral to be seen within two weeks

3) Orange-referral to be seen within 48 hours

4) Pink-immediate referral

\section{THE BOTTOM LINE}

- Nearly all possible childhood cancers require referral for investigation, as primary care testing is only of use in sarcomas (very urgent ultrasound or $\mathrm{x}$ ray) and leukaemias (full blood counts)

- Abnormal primary care tests for cancer all warrant urgent referral

\section{thebmj.com}

- Read more NICE guidelines in The BMJ at http://www.bmj.com/ specialties/guideline-summaries

\section{Possible cancers}

\section{Primary care investigation}

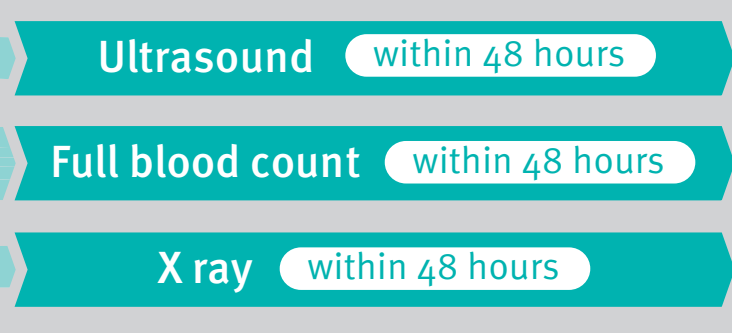

\section{Brain}

or CNS

cancer

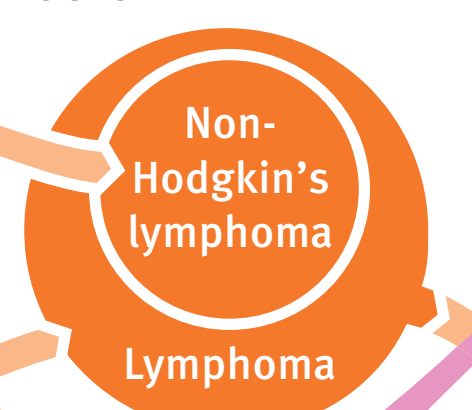

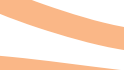
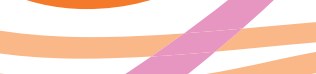

Wilms' tumour
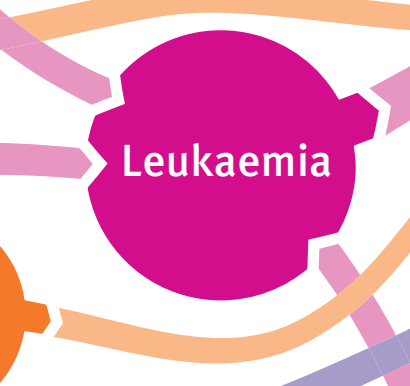

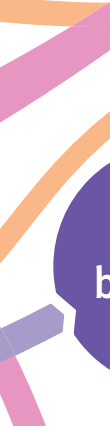

Retino-

blastoma

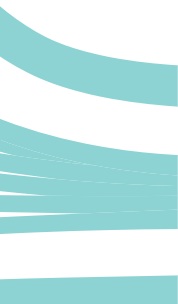

\section{Referral to specialist}
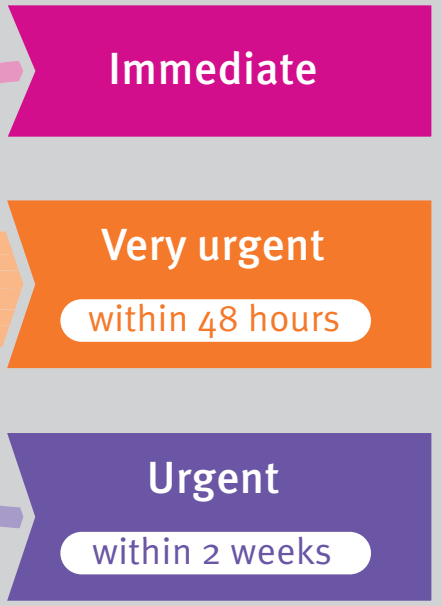

\section{Parental concern}

Take into account insight and knowledge of parents and carers when considering making a referral for suspected cancer in a child or young person. Consider referral even if symptoms are most likely to have a benign cause.

\section{Bone}

sarcoma 